\title{
Characterization of catalytic chemical vapor-deposited SiCN thin film coatings
}

\author{
Suresh Neethirajan ${ }^{1 *}$, Takahita Ono ${ }^{2}$ and Esashi Masayoshi ${ }^{2}$
}

\begin{abstract}
Silicon carbonitride thin films of 480 to $730-\mathrm{nm}$ thicknesses were grown on silicon substrate using ammonia and hexamethyldisilazane gas sources using catalytic chemical vapor deposition process. Compositions of silicon, carbon and nitrogen in the SiCN films were varied by changing the flow rate of ammonia gas. The effect of deposition conditions on the structural, optical and mechanical properties of SiCN thin films was examined. X-ray photoelectron spectroscopy analysis indicated that the higher flow rate of ammonia gas results in higher nitrogen and lower carbon content in the deposited thin films. The measurement of stress as a function of substrate temperature in the SiCN film showed that the stress changes from compressive to tensile in the range of $275^{\circ} \mathrm{C}$ to $325^{\circ} \mathrm{C}$. With these preliminary characterization tests, it is expected that SiCN nano-thin films can be used for developing sensors for harsh environment.
\end{abstract}

Keywords: SiCN, Catalytic chemical vapor deposition, Thin films, XPS

\section{Findings}

Polymer-derived ceramic materials such as silicon carbonitride $(\mathrm{SiCN})$ are gaining momentum because of their excellent thermal and mechanical properties at high temperatures. In addition, the electrical conductivity of $\mathrm{SiCN}$ can be tailored and characterized to suit specific application needs. These unique properties make $\mathrm{SiCN}$ a best choice for sensor applications. SiCN has the potential to be used for making heat flux sensors [1], health monitoring sensors for turbines and power generation systems [2] and high temperature pressure transducers [3]. Because of temperature dependence on the resistance of the $\mathrm{SiCN}$ film, the potential of making gas/ temperature sensor using $\mathrm{SiCN}$ films is enormous. For high temperature, corrosive and harsh environmental applications in the agricultural and food industry, SiCNbased sensors are preferred.

Experimental methods for making thin films of $\mathrm{SiCN}$ to facilitate sensor fabrication are being researched worldwide. Radio frequency magnetron sputtering [4,5], pulsed laser deposition [6], plasma-enhanced chemical vapor deposition (CVD) [7], microwave plasma-enhanced CVD and electron

\footnotetext{
* Correspondence: s.neethi@uoguelph.ca

${ }^{1}$ Biological Engineering, University of Guelph, 50 Stone Road East, Guelph, ON, N1G 2W1, Canada

Full list of author information is available at the end of the article
}

cyclotron resonance plasma CVD [8], ion beam sputtering [9], hotwire CVD [10] and other methods of depositing $\mathrm{SiCN}$ films have been explored. The advantages of catalytic CVD over PECVD and other deposition techniques include higher deposition rate with lower strain, reduced thermally induced stress on the substrate and low processing cost. Parameter regimes such as influence of flow rates of target gas and variation in substrate temperature need to be identified for effective deposition of $\mathrm{SiCN}$ thin films. This work focuses on the optimization of SiCN films using hexamethyldisilazane (HMDS) and ammonia gasses, and investigation of the effect of deposition conditions. The correlation between process parameters and the structural, optical and mechanical properties of the fabricated $\mathrm{SiCN}$ thin films with various deposition conditions are reported.

\section{Experimental details}

The SiCN films were deposited using a catalytic CVD reactor (Figure 1; custom built by Universal Systems Co., Tokyo, Japan) on $n$ type (100)-oriented Si wafer of 380- $\mu \mathrm{m}$ thickness. Prior to deposition, silicon wafers were cleaned using RCA cleaning process. Tungsten wires of $0.5-\mathrm{mm}$ diameter were used as a catalytic filament and were heated by flowing current. The distance between substrates and filament was set to be $5 \mathrm{~cm}$. The filament temperature was controlled by flowing current through the filament and 

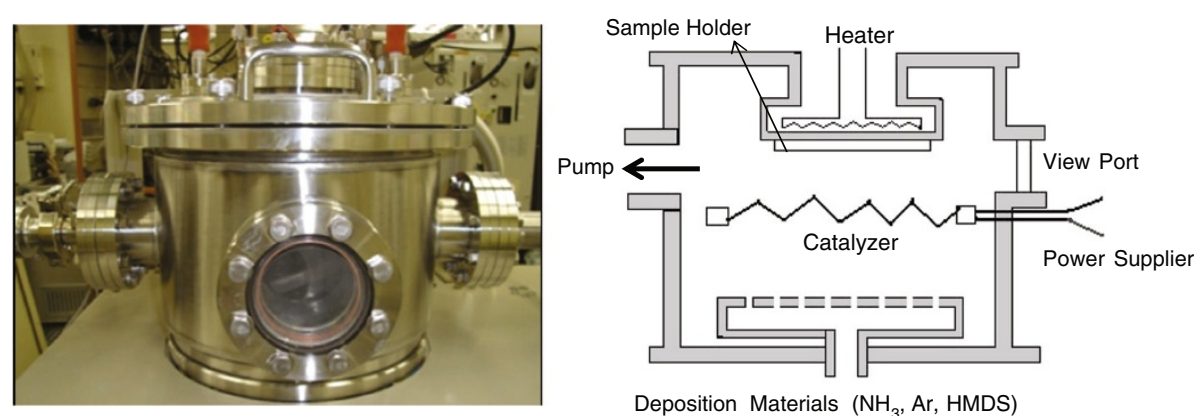

Figure 1 Photograph and schematic cross-section of the custom-built catalytic CVD apparatus.

was measured by a digital pyrometer (Chino 760, Tokyo, Japan). The substrate was heated using an embedded heater, and the temperature was measured using a thermocouple attached to the substrate holder. The CVD system consists of a HMDS liquid tank. Argon was used as a carrier gas at constant flow rate to carry HMDS into the reaction chamber. The flow of $\mathrm{Ar}+\mathrm{HMDS}$ and $\mathrm{NH}_{3}$ was controlled by mass flow controllers in both gas lines. Before the deposition of a thin film, the reaction chamber was evacuated using a turbo molecular pump.

The filament temperature was maintained at $1,550^{\circ} \mathrm{C}$. The varying deposition conditions are shown in Table 1. The deposition time was between 10-15 min. The chemical composition of the films was determined by Xray photoelectron spectroscopy using $\mathrm{MgK} \alpha$ radiation. The refractive index was obtained using a prism coupler (Metricon Model 2010, Metricon Corporation, NJ, USA). Film thickness was measured using FE-SEM (Model S4500, Hitachi High-Technologies Corporation, Tokyo, Japan). SiCN film residual stress was calculated by measuring the radius of wafer curvature before and after film deposition using a thin film stress measurement system (Tencor P10 Surface Profiler, Tencor Systems Inc., Ontario, Canada) according to Stoney's equation [11]:

$$
\sigma=\frac{1}{6}\left(\frac{E}{1-\gamma}\right) \frac{D}{t}\left(\frac{1}{r}-\frac{1}{r 1}\right)
$$

where $E$ is the Young's modulus for substrate, and $\gamma$ is its Poisson's ratio; $D$ and $t$ are the thicknesses of the substrate

Table 1 Deposition conditions of SiCN films

\begin{tabular}{ll}
\hline Condition & Value \\
\hline Material & $\mathrm{HMDS}+\mathrm{Ar}_{,} \mathrm{NH}_{3}$ \\
\hline $\mathrm{HMDS}+\mathrm{Ar}$ flow rate & $5 \mathrm{sccm}$ \\
\hline $\mathrm{NH}_{3}$ flow rate & $0-60 \mathrm{sccm}$ \\
\hline Background pressure & $0.13 \mathrm{~Pa}$ \\
\hline Substrate pressure & $200^{\circ} \mathrm{C}, 300^{\circ} \mathrm{C}$ \\
\hline Filament pressure & $1550^{\circ} \mathrm{C}$ \\
\hline Filament-sample pressure & $5 \mathrm{~cm}$ \\
\hline
\end{tabular}

and the film, respectively; $r 1$ and $r$ are the radius of wafer curvature before and after film deposition, respectively.

\section{Results and discussion}

\section{Structural property}

In a $\mathrm{SiCN}$ thin film, $\mathrm{C}-\mathrm{N}$ bonds contribute to electrical conductivity and higher hardness, while $\mathrm{Si}-\mathrm{C}$ bonds complement mechanical property. Hence, the properties of $\mathrm{SiCN}$ films can be tuned for need-based applications by changing the composition ratio. The influence of ammonia flow rate on the chemical composition ratio of the SiCN films are shown in Figure 2. Films deposited using lower than 10 -sccm $\mathrm{NH}_{3}$ flow rate contains more than $40 \%$ carbon content. Nitrogen content gradually increased from $23 \%$ to $39 \%$ as the flow rate increased, while the carbon content decreased from $41 \%$ to $19 \%$ at $200^{\circ} \mathrm{C}$ substrate temperature. The comparison between deposition condition of $200^{\circ} \mathrm{C}$ and $300^{\circ} \mathrm{C}$ substrate temperatures reveals that silicon concentration decreased with increasing temperature. This analysis indicates that the carbon content in the $\mathrm{SiCN}$ films can be increased by increasing HMDS flow rate or by decreasing ammonia flow rate or both. The film thickness was measured using an optical profiler and was found to be ranging from 480 to $720 \mathrm{~nm}$.

\section{Optical property}

The refractive index of $\mathrm{SiCN}$ thin films measured using interferometer varied in the range of 2.5 to 2.2 for $200^{\circ} \mathrm{C}$ substrate temperature. The refractive index decreased with an increase in flow rate of ammonia. This may be due to the increased nitrogen concentration in the $\mathrm{SiCN}$ thin film. The value of refractive index decreased with increasing substrate temperature (Figure 3). For fabrication of micro-mirrors and anti-reflective coatings of solar cell applications, the refractive index of $\mathrm{SiCN}$ can be tuned and tailored.

\section{Mechanical property}

The stress as a function of substrate temperature in the $\mathrm{SiCN}$ film is shown in Figure 4. The stress is compressive 


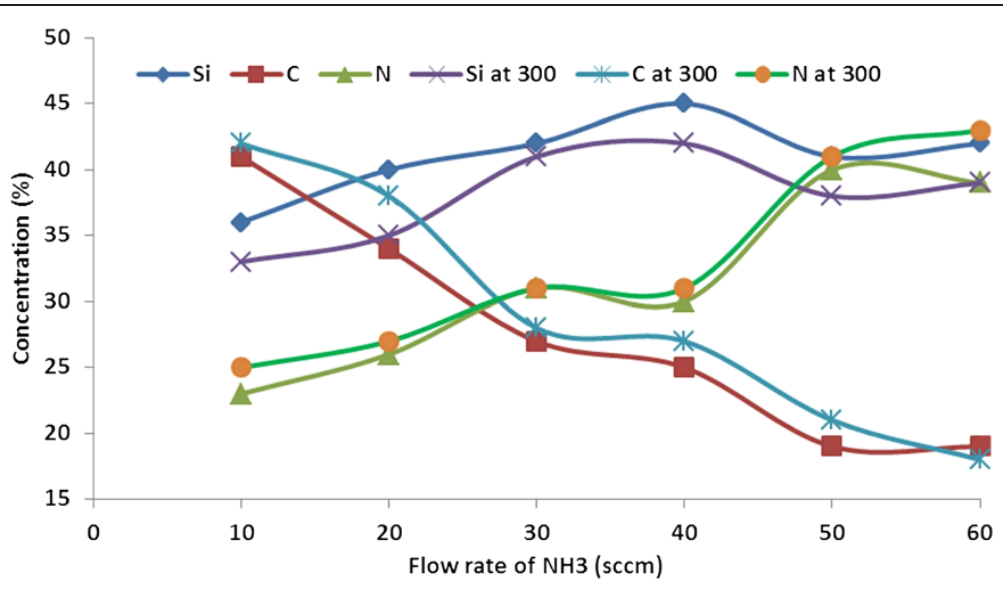

Figure 2 Relationship between ammonia flow rate and chemical composition of SiCN films.

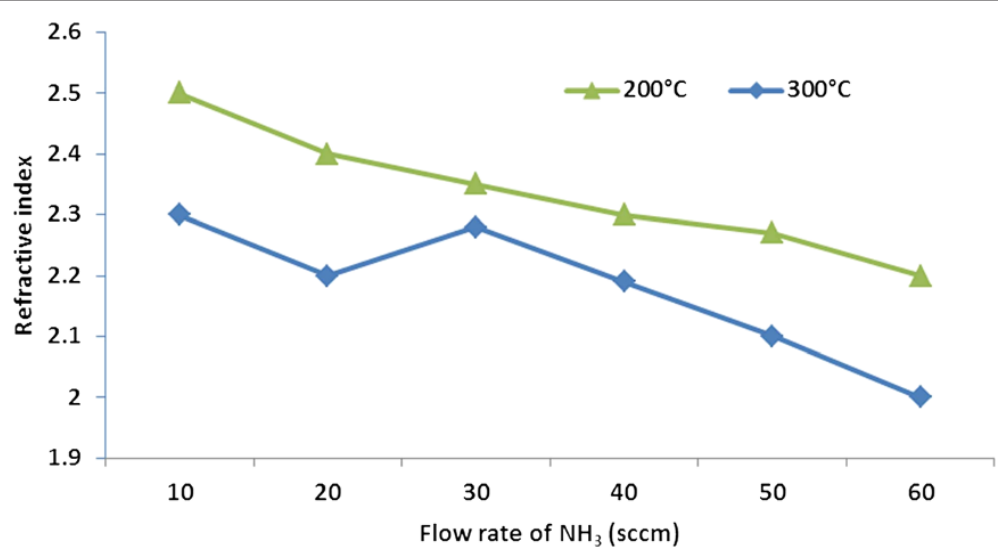

Figure 3 Variation of refractive index with ammonia flow rate for SiCN films.

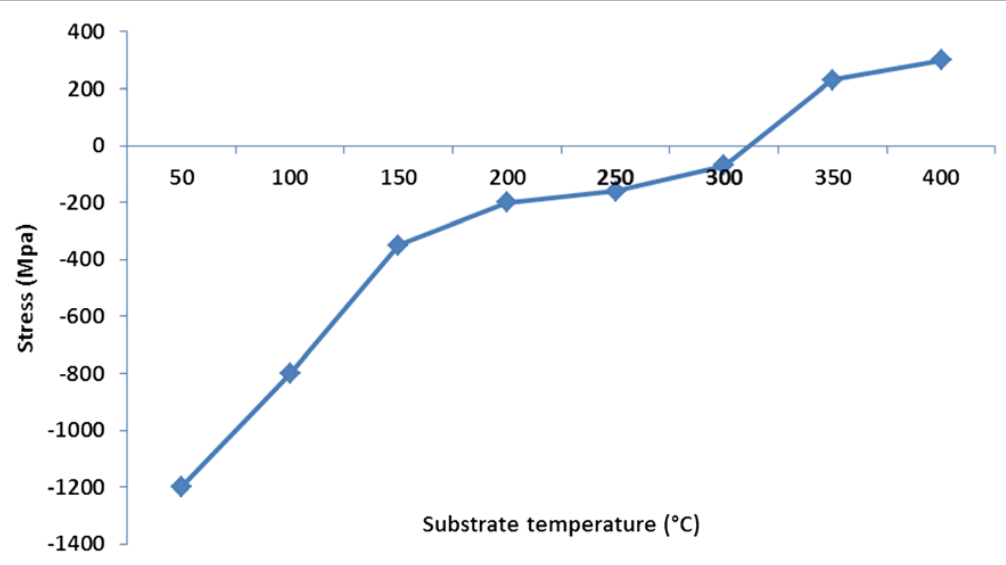

Figure 4 Variation of stress with substrate temperature for SiCN films. 
below $330^{\circ} \mathrm{C}$, and it becomes tensile as the temperature increases. There is a steady increase in tensile stress once the temperature reaches $350^{\circ} \mathrm{C}$ and above. The value of stress at $50^{\circ} \mathrm{C}$ is $1,200 \mathrm{MPa}$ compressive and at $400^{\circ} \mathrm{C}$ is $300 \mathrm{MPa}$ tensile. The stress changes from compressive to tensile in the range of $275^{\circ} \mathrm{C}$ to $325^{\circ} \mathrm{C}$. Higher tensile stress on cantilever structures made of $\mathrm{SiCN}$ thin films will lead to fracture, while compressive stress will cause buckling. Hence, during fabrication of $\mathrm{SiCN}$ film-based microdevices, it is optimum to do the deposition at $330^{\circ} \mathrm{C}$.

\section{Conclusion}

Silicon carbonitride films were successfully fabricated by catalytic chemical vapor deposition using hexamethyldisilazane and ammonia as source gasses. The chemical composition ratio as well as the refractive index of $\mathrm{SiCN}$ film can be changed by altering the flow rate of ammonia gas. The correlation between stress and substrate temperature indicates that the optimum deposition temperature of $\mathrm{SiCN}$ film for the fabrication of cantilevers and other micro-structures is around $330^{\circ} \mathrm{C}$.

\section{Competing interests}

The authors declare that they have no competing interests.

\section{Acknowledgments}

The authors gratefully acknowledge the Department of Nanomechanics, Tohoku University, Japan for providing access to clean room and equipment facilities. Authors also thank the Japan Society for the Promotion of Science and the Natural Sciences and Engineering Research Council of Canada for funding this study.

\section{Author details}

${ }^{1}$ Biological Engineering, University of Guelph, 50 Stone Road East, Guelph, ON, N1G 2W1, Canada. ' Graduate School of Engineering, Tohoku University, 6-6-01 Aramaki-Aza-Aoba, Sendai 980-8579, Japan.

\section{Authors' contributions}

SN was involved with the experimental design, collection of data and data analysis, and authored the manuscript. TO was involved in data collection $\mathrm{TO}$ and EM conceived of the study and participated in its design and coordination. All authors have read and approved the final manuscript.

Received: 8 April 2012 Accepted: 7 June 2012

Published: 7 June 2012

\section{References}

1. Nagaiah, N.R, Kapat, J.S, An, L., Chow, L.: Novel polymer derived ceramichigh temperature heat flux sensor for gas turbine environment. J. Phys: Conf. Series 34, 458-463 (2006)

2. Leo, A., Andronenko, S., Stiharu, I., Bhat, R.B.: Characterization of thick and thin film SiCN for pressure sensing at high temperatures. Sensors. 10 1338-1354 (2010)

3. Liew, L., Saravanan, R.A, Bright, V.M, Dunn, M.L, Daily, J.W, Raj, R.: A novel micro glow plug fabricated from polymer-derived ceramics: in situ measurement of high-temperature properties and application to ultrahigh-temperature ignition. Sens. Actu. A: Phys. 15, 246-262 (2003)

4. Xie, E., Ma, Z., Lin, H., Zhang, Z., He, D.: Preparation and characterization of SiCN films. Opt. Mat. 23, 151-156 (2003)

5. Sundaram, K.B. Alizadeh, Z. Todi, R.M., Desai, V.H.: Investigations on hardness of rf sputter deposited SiCN thin films. Mater Sci Eng 368, 103-108 (2004)

6. Park, N., Kim, S.H, Sung, G.Y.: Band gap engineering of SiCN film grown by pulsed laser deposition. J. App. Phy. 94, 2725-2728 (2003)
7. Fischer, L.M, Wilding, N., Gel, M., Evoy, S.: Low-stress silicon carbonitride for the machining of high-frequency nanomechanical resonators. J. Vac. Sci. Tech B. 25, 33-37 (2007)

8. Chen, L.C, Chen, K.H, Wei, S.L, Kichambare, P.D, Wu, J.J, Lu, T.R, Kuo, C.T.: Crystalline SiCN: a hard material rivals to cubic BN. Thin Solid Films. 355, 112-116 (1999)

9. Zhou, F., Yue, B., Wang, X., Wu, X., Zhuge, L.: Surface roughness, mechanical properties and bonding structure of silicon carbonitride films grown by dual ion beam sputtering. J. Alloy. Compd. 492, 269-276 (2010)

10. Nakayama, H., Ito, M.: Super H2O-barrier film using Cat-CVD (HWCVD)-grown SiCN for film-based electronics. Thin Solid Films. 519, 4483-4486 (2011)

11. Stoney, G.G.: The tension of metallic films deposited by electrolysis. Proc. R. Soc. London, Ser. A 82, 172-175 (1909)

doi:10.1186/2228-5326-2-4

Cite this article as: Neethirajan et al:: Characterization of catalytic chemical vapor-deposited SiCN thin film coatings. International Nano Letters 2012 2:4.

\section{Submit your manuscript to a SpringerOpen ${ }^{\circ}$ journal and benefit from:}

- Convenient online submission

- Rigorous peer review

- Immediate publication on acceptance

- Open access: articles freely available online

- High visibility within the field

- Retaining the copyright to your article

Submit your next manuscript at $>$ springeropen.com 